\title{
Otimização multiobjetivo da operação de sistemas de distribuição de água com bombas de rotação variável
}

\author{
Multiobjective optimization of the operation of \\ water distribution systems with variable speed pumps
}

Layara de Paula Sousa Santos ${ }^{1} \odot$, Ricardo Santos Coutinho ${ }^{2} \oplus$, Alexandre Kepler Soares ${ }^{3 *} \odot$

$\square$

\begin{abstract}
RESUMO
Ante o crescimento populacional urbano e a importância da água como recurso natural limitado, verifica-se a necessidade de implementar técnicas com a finalidade de reduzir os custos operacionais dos sistemas de distribuição de água e garantir abastecimento adequado. A otimização da operação de bombas pode ser utilizada com o propósito de atender às demandas de consumo com menor custo energético, além de maximizar a confiabilidade hidráulica. Neste trabalho, um modelo híbrido de otimização/simulação foi desenvolvido tendo como suporte os algoritmos genéticos multiobjetivo e o simulador hidráulico EPANET. O método Non-dominated Sorting Genetic Algorithm II (NSGA II) foi utilizado para a otimização da operação de bombas de rotação variável, ou seja, as variáveis de decisão do problema foram as rotações das bombas para cada hora ao longo do dia. Uma modificação do simulador hidráulico EPANET original, que não computa corretamente o rendimento de bombas de rotação variável, foi empregada para que as potências de cada bomba e, consequentemente, o custo da energia elétrica fossem calculados corretamente. Conjuntos de soluções não dominadas (frente Pareto) foram obtidos considerando-se, primeiramente, a penalidade de pressão negativa nos nós e, posteriormente, as penalidades de pressão negativa nos nós e o fechamento/desligamento de tubos e/ou bombas. Aplicou-se o método à rede hipotética denominada Anytown, e custos menores, considerando tarifas brasileiras, foram obtidos.
\end{abstract} Palavras-chave: otimização multiobjetivo; bombas de rotação variável; custo energético; confiabilidade hidráulica.

\begin{abstract}
Faced with the urban population growth and the importance of water as a limited natural resource, there is a need to implement techniques to reduce the operational costs of water distribution systems and ensure adequate supply. The optimization of pump operation can be used to meet the demands of consumption with a lower energy cost, in addition to maximizing hydraulic reliability. In this work, a hybrid optimization/simulation model was developed based on the multiobjective genetic algorithms and the EPANET hydraulic simulator. The NSGA II (Non-dominated Sorting Genetic Algorithm II) method was used to optimize the operation of variable rotation pumps, that is, the decision variables of the problem were the rotation of the pumps for each hour throughout the day. A modification of the original EPANET hydraulic simulator, which does not correctly compute the efficiency of variable-speed pumps, was employed so that the power of each pump, and consequently the cost of electric power, was calculated correctly. Non-dominated solution sets (Pareto Front) were obtained considering first the negative pressure penalty at the nodes and, subsequently, the negative pressure penalties at the nodes and the closure/shutdown of tubes and/or pumps. The method has been applied in the hypothetical network called ANYTOWN and lower energy costs were obtained considering Brazilian energy tariffs.
\end{abstract}

Keywords: multiobjective optimization; variable speed pumps; energy cost; hydraulic reliability.

\section{INTRODUÇÃO}

A distribuição de água potável é um serviço fundamental oferecido para a sociedade. Estima-se que, até 2030, a demanda de água excederá a capacidade de oferta em $40 \%$ dadas as práticas atuais de gestão de recursos hídricos (ADDAMS et al., 2009). Com o

aumento da urbanização, os governos apresentam dificuldades em melhorar a infraestrutura dos sistemas de distribuição de água no mesmo ritmo da expansão populacional, mas mudar a maneira como operam tais sistemas pode trazer melhorias significativas (CONNOR, 2015).

'Universidade Federal de Goiás - Goiânia (GO), Brasil.

${ }^{2}$ Ministério Público do Estado de Goiás - Goiânia (GO), Brasil.

3Universidade de Brasília - Brasília (DF), Brasil.

*Autor correspondente: aksoares@gmail.com

Recebido: 14/09/2O17 - Aceito: 1O/07/2O19 - Reg. ABES: 185139 
Um dos custos mais importantes nos sistemas de distribuição de água está relacionado à eletricidade usada para bombear água. De fato, cerca de 2 a 3\% do consumo global de energia é usado nos sistemas de distribuição de água, que são responsáveis por até $30 \%$ dos custos operacionais totais desses sistemas. Portanto, é importante que os provedores de serviços de água desenvolvam planos eficientes para reduzir os custos (LIU et al., 2012). O consumo de energia nesses sistemas está relacionado à demanda de água, uma vez que a energia é consumida principalmente nas etapas de transporte e distribuição. Como resultado, ocorre um aumento na carga do sistema energético nas horas de pico do consumo de água (CHANG et al., 2018). A maioria dos sistemas de distribuição de água exige a operação de bombas para fornecer a quantidade necessária de água com a pressão adequada aos consumidores finais. De acordo com Walski et al. (2003), os sistemas de distribuição equipados com estações de bombeamento são caracterizados por um consumo superior a $60 \% \mathrm{da}$ energia consumida pela operação de todo o sistema de abastecimento em grandes centros urbanos. Nesse aspecto, os sistemas de bombeamento têm potencial significativo para melhorias na eficiência energética (ZHANG; XIA; ZHANG, 2012).

Para isso, desenvolveram-se vários métodos de operação com a finalidade de minimizar os custos com energia e maximizar a confiabilidade do sistema, e a substituição de bombas de rotação constante por bombas de rotação variável na modelagem hidráulica tem obtido resultados mais fidedignos para a redução de custos operacionais sem exigir intervenções onerosas na infraestrutura do sistema (GIUSTOLISI; LAUCELLI; BERARDI, 2013).

A otimização multiobjetivo com bombas de rotação variável é fundamental para reduzir os custos com energia elétrica, além de garantir um serviço de abastecimento de água satisfatório. Nesse aspecto, Kurek e Ostfeld (2014) descreveram um modelo multiobjetivo para analisar o custo de bombeamento e a qualidade da água na rede Anytown. Impuseram restrições para vazões e pressões e armazenamento nos tanques.

De Paola et al. (2016) utilizaram uma abordagem de otimização multiobjetivo adaptada ao problema de programação da bomba. O modelo interage com simulador hidráulico EPANET 2.0, para verificar as restrições hidráulicas e avaliar os desempenhos nos horários selecionados. Aplicou-se o modelo na rede Anytown, na qual quatro bombas foram instaladas. Os resultados demonstraram uma redução de aproximadamente $60 \%$ dos custos.

Coutinho e Soares (2017) observaram que nas simulações com bombeamento com eficiência variável, os resultados de eficiência previstos pela versão modificada do simulador hidráulico foram coerentes com os valores teóricos esperados. Assim, os autores concluíram que a versão modificada do EPANET 2.0 representa de forma mais acurada o comportamento de bombas de rotação variável.
Candelieri, Perego e Archetti (2018) consideraram o problema de otimização de programação de bombas de rotação variável utilizando a rede Anytown. A contabilização de padrões de demanda e preço de energia permitiram economias de custos. Utilizou-se o simulador EPANET para calcular o custo de energia associado a um cronograma de bombeamento para verificar se as restrições hidráulicas não são violadas e se a demanda é atendida.

O modelo multiobjetivo proposto neste trabalho visa obter uma ferramenta que minimize o custo de energia elétrica nas estações elevatórias e proporcione o aumento da confiabilidade do sistema por meio da utilização de bombas de rotação variável.

\section{BOMBAS DE ROTAÇÃO VARIÁVEL}

Pelo fato de a bomba de rotação variável ser executada em velocidades diferentes, resulta em uma alteração na curva característica da bomba. Como o funcionamento destas pode ser adaptado para cumprir os requisitos do sistema, geralmente proporcionam mais eficiência do que as bombas convencionais de velocidade fixa (LINGIREDDY; WOOD, 1998).

Quando a velocidade da bomba é alterada, a eficiência geralmente é determinada por meio de uma curva de eficiência de fluxo na velocidade nominal da bomba e de leis de semelhança, que descrevem a relação entre as variáveis envolvidas no desempenho, tais como vazão, carga total e velocidade de rotação da bomba (SIMPSON; MARCHI, 2013). As características adimensionais da bomba são apresentadas pelas Equações 1, 2 e 3:

$C_{Q}=\frac{Q}{N D^{3}}$

$C_{H}=\frac{g H}{N^{2} D^{2}}$

$C_{p}=\frac{P}{\rho N^{3} D^{5}}$

Em que:

$C_{Q}=$ o coeficiente adimensional de vazão;

$C_{H}=$ o coeficiente adimensional de altura manométrica;

$C_{P}=$ o coeficiente adimensional de potência;

$Q=$ a vazão da bomba $\left(\mathrm{m}^{3} / \mathrm{s}\right)$;

$H=$ altura manométrica da bomba (m);

$P=$ a potência da bomba $(\mathrm{W})$;

$N$ = a velocidade de rotação da bomba (rpm);

$D=\mathrm{o}$ diâmetro do rotor $(\mathrm{m})$

$g=$ a aceleração da gravidade $\left(\mathrm{m} / \mathrm{s}^{2}\right)$;

$\rho=$ a massa específica do líquido $\left(\mathrm{kg} / \mathrm{m}^{3}\right)$. 
A Equação 4 representa a eficiência de forma indireta, isso porque a potência é proporcional ao produto da vazão e da altura manométrica, divididos pela eficiência, $\eta$ :

$P=\frac{\rho g Q H}{\eta}$

As leis de semelhança também podem apresentar um caso particular de bombas com características adimensionais que descrevem mudança de velocidade e, dessa forma, são válidas para situação de diâmetro constante. As Equações 5, 6 e 7 mostram que a vazão, a altura manométrica e a potência são funções lineares, quadráticas e cúbicas, respectivamente, da velocidade de rotação da bomba, $N$ :

$\frac{Q_{1}}{Q_{2}}=\frac{N_{1}}{N_{2}}$

$\frac{H_{1}}{H_{2}}=\left(\frac{N_{1}}{N_{2}}\right)^{2}$

$\frac{P_{1}}{P_{2}}=\left(\frac{N_{1}}{N_{2}}\right)^{3}$

O simulador hidráulico EPANET não utiliza as Equações 3 e 7 para calcular a potência de uma bomba que funciona em velocidades diferentes. Ao invés disso, utiliza a curva de eficiência referente à vazão versus velocidade nominal da bomba normalmente fornecida pelo fabricante. Quando a velocidade da bomba é reduzida, a curva referente à eficiência versus vazão desloca-se para a esquerda e estreita-se, já a curva $\eta$ - $C_{Q}$ permanece constante e mantém o melhor ponto de eficiência.

\section{METODOLOGIA}

Neste trabalho, desenvolveu-se um modelo para a obtenção de regras operacionais de sistemas de abastecimento de água visando minimizar os custos de energia do bombeamento e maximizar a confiabilidade de sistemas de distribuição de água. O modelo proposto foi concebido com base nos algoritmos genéticos multiobjetivo, por se tratar de uma técnica recente e que tem mostrado resultados promissores. Como método auxiliar, utilizou-se o simulador hidráulico EPANET 2.0, considerando-se a versatilidade, o fato de ser um programa de domínio público, além de ser testado e recomendado pela comunidade científica.

O programa de otimização multiobjetivo deverá interagir com o simulador hidráulico EPANET 2.0 na busca por melhores soluções. A última etapa do modelo é denominada etapa de decisão e tem como objetivo apresentar soluções não dominadas e transformá-las em planos de operação.

\section{Modelo computacional proposto}

O modelo proposto nesta pesquisa é resolvido interligando um otimizador baseado em algoritmos evolucionários multiobjetivo (Nondominated Sorting Genetic Algorithm II - NSGA-II) (DEB et al., 2002) e um simulador hidráulico fundamentado no código original e alterado do EPANET 2.0 (ROSSMAN, 2000).

As avaliações hidráulicas constituem parte fundamental na avaliação dos valores das funções objetivo. Dessa forma, há a necessidade de incorporar um simulador hidráulico à rotina computacional com a finalidade de avaliar as variáveis de estado, como pressões e vazões do sistema. Neste estudo, utilizou-se o simulador proposto por Coutinho e Soares (2017), que contém as modificações necessárias para a correção do cálculo da eficiência de bombas de rotação variável no EPANET 2.0.

Para formulação do problema de otimização, as penalidades têm a finalidade de introduzir ao modelo limites hidráulicos e operacionais previamente estabelecidos de modo que as soluções que tenham esses limites violados sejam identificadas e descartadas.

\section{Seleção dos parâmetros de entrada do algoritmo genético}

Os parâmetros de entrada dos algoritmos genéticos são constituídos da população inicial, do número de gerações e dos operadores genéticos de seleção, mutação e recombinação. De acordo com Sousa (2013), a população inicial corresponde à quantidade de vetores solução gerada aleatoriamente em cada iteração. Já o número de gerações é utilizado como critério de parada no processo de otimização. Os operadores genéticos representam as melhores soluções desenvolvidas pelos algoritmos, em que os indivíduos mais aptos se reproduzem, passando os valores de suas variáveis de decisão para as iterações posteriores. A taxa de mutação é responsável por promover a diversidade dos vetores soluções, por meio da inclusão de novas soluções na população. Já a recombinação é responsável por criar novas soluções dado o cruzamento das soluções correntes por uma simples permuta ou pela combinação de características dos vetores pais. Pelas variações produzidas, é possível explorar novos pontos no espaço de busca das soluções.

Os parâmetros de entrada utilizados são compostos de uma população inicial de 200 indivíduos, número de gerações igual a 1.000, probabilidade de mutação igual a 0,01 e probabilidade de recombinação igual a 0,75 .

\section{Formulação do problema}

A otimização operacional de sistemas de abastecimento de água é abordada como um problema de otimização multiobjetivo, cujas variáveis de decisão, funções objetivo e ordenamento das soluções são apresentadas a seguir.

São consideradas como variáveis de decisão as velocidades de rotação $W_{b}$ de cada bomba $b$, para cada intervalo de tempo $t$, ao longo de 
um ciclo operacional $T$ de 24 horas, restritas ao intervalo contínuo $W_{b} \in\left(\mathrm{w}_{\mathrm{b}} \mathrm{min} ; \mathrm{w}_{\mathrm{b}} \mathrm{máx}\right)$. Para cada bomba pertencente ao conjunto $\mathrm{B}$, tem-se um vetor $\Omega$ que representa o seu agendamento operacional, conforme Equação 8.

$\Omega=\left\{\left[w_{b}(0) ; \ldots ; w_{b}(T)\right]\right\}$ parab $\left.\in B\right\}$.

As duas funções objetivo consideradas na otimização operacional são a minimização do custo da energia consumida pela operação das bombas do sistema e a maximização da confiabilidade da rede.

\section{Eficiência energética}

A determinação ou a comparação de custos de energia de bombeamento para diferentes cenários tarifários não é objetivo desta pesquisa. $\mathrm{O}$ foco é identificar a relação perda-ganho (trade-off) entre os custos de energia e a confiabilidade do sistema. Adotou-se uma tarifa base de energia elétrica $C$ para todas as estações elevatórias do sistema de abastecimento de água. Contudo, com o intuito de preservar a característica de diferenciação horária (períodos de ponta e fora de ponta) da estrutura tarifária brasileira, a tarifa base de energia será multiplicada por um fator $\mathrm{K} \mathrm{em}$ cada intervalo de tempo do ciclo operacional. Assim, o custo de energia $J_{1}$ consumido pelas bombas do sistema pode ser obtido pela Equação 9.

$J_{1}=\sum_{t=0}^{T} \sum_{b=1}^{n b}\left(K_{t} C\right)\left(\frac{\gamma Q_{t, b} H_{t, b}}{\eta_{t, b}}\right)$

Em que:

$t=\mathrm{o}$ número de intervalos de tempo;

$T=$ o número de intervalos de tempo do ciclo operacional;

$b=$ o número associado a cada bomba;

$n_{\mathrm{b}}=\mathrm{o}$ número de bombas existentes no sistema;

$K=\mathrm{o}$ fator temporal associado à tarifa base de energia;

$C=$ a tarifa base de energia;

$\gamma=$ o peso específico da água;

$Q=$ a vazão da bomba;

$H=$ a altura manométrica da bomba;

$\eta=\mathrm{o}$ rendimento da bomba.

Adotou-se o valor de R \$255,88/MWh para a tarifa de energia, correspondente à tarifa média nacional de fornecimento para os serviços públicos de água, esgoto e saneamento (ANEEL, 2014). Já o fator temporal $K$, associado à tarifa de energia, tem valor de 1,7 para o período de ponta (intervalo das 18 às $21 \mathrm{~h}$ ) e 0,9 para o período fora de ponta.

\section{Confiabilidade hidráulica}

A confiabilidade hidráulica consiste na probabilidade de suprir a demanda dos consumidores, com distribuição de água em quantidade, qualidade e carga de pressão adequadas, nos locais e horários apropriados. O cálculo requer dados referentes aos componentes do sistema de abastecimento, assim como impactos associados à demanda (OSTFELD, 2004).

Pela dificuldade de incorporar diretamente as medidas de confiabilidade ao processo de otimização, medidas alternativas de confiabilidade têm sido utilizadas, tais como a entropia e a resiliência. A entropia mede o grau de uniformidade das vazões. De acordo com Formiga, Chaudhry e Vieira (2006), esquemas de distribuição de água sem caminhos preferenciais de fluxo dentro do sistema terão um valor de entropia maior, o que significa que tendem a ser menos suscetíveis às falhas no caso de quebra de um trecho. No entanto, os autores observaram que a entropia possui limitações ante a impossibilidade de comparar valores entre problemas diferentes, já que é particular para cada problema. Outro aspecto negativo está nos valores muito próximos de entropia, pela formulação na base logarítmica.

Todini (2000) propôs o uso da resiliência como medida alternativa de confiabilidade, a qual demonstra a capacidade do sistema em atender às demandas, ainda que ocorram situações de falha mecânica ou hidráulica. Posteriormente, Jayaram e Srinivasan (2008) modificaram o índice de resiliência de Todini (2000), para otimizar projeto e reabilitar redes de abastecimento de água.

Neste trabalho, realizou-se a avaliação da confiabilidade por meio de uma medida substituta, especificamente o índice de resiliência (IR) de Todini (2000) (Equação 10). A escolha desse índice se deve ao seu desempenho na quantificação da confiabilidade hidráulica de sistemas de abastecimento de água quando comparado com outros indicadores comumente citados pela literatura (entropia do fluxo, resiliência da rede e índice de resiliência modificado), conforme observado no trabalho de Atkinson et al. (2014). Assim, para um ciclo operacional completo, a função objetivo relacionada à confiabilidade hidráulica do sistema é dada por $\mathrm{J}_{2}$ (Equação 11). Ressalta-se que, quanto maior o valor de $\mathrm{J}_{2}$, maior é a confiabilidade do sistema em fornecer aos consumidores um nível de serviço adequado.

$$
I R_{t}=\frac{\sum_{i \in N}^{n m} Q_{i, t}\left(H_{i, t}-H_{i, t}^{*}\right)}{\sum_{r \in R}^{n r} Q_{r, t} H_{r, t}+\sum_{p \in P}^{n p} \frac{P_{p, t}}{\gamma}-\sum_{i \in N}^{n n} Q_{i, t} H_{i, t}^{*}}
$$

$J_{2}=\sum_{t=0}^{T} I R_{t}$

Em que:

$t=\mathrm{o}$ número do intervalo de tempo;

$T$ = o número de intervalos de tempo do ciclo operacional;

$i=$ o número associado a cada nó;

$N=$ o conjunto de todos os nós do sistema;

$n n=\mathrm{o}$ número de nós existentes no sistema; 
$Q_{i}=$ a demanda no nó $i$;

$H_{i}=$ a pressão disponível no nó $i$;

$H_{i}^{*}=$ a pressão requerida no nó $i$;

$r=\mathrm{o}$ número associado a cada reservatório que abastece o sistema;

$R=$ o conjunto de todos os reservatórios do sistema;

$n r=$ o número de reservatórios existentes no sistema;

$Q_{r}=$ a vazão fornecida pelo reservatório $r$ ao sistema;

$H_{r}=$ a carga piezométrica no reservatório $r$;

$p=$ o número associado a cada bomba;

$P=$ o conjunto de todas as bombas do sistema;

$n p=$ o número de bombas existentes no sistema;

$P_{P}=$ a energia, em termos de potência, introduzida no sistema pela bomba $p$;

$\gamma=$ o peso específico da água.

\section{Rede de distribuição de água}

O modelo de otimização proposto foi aplicado à rede hipotética Anytown, conforme Figura 1 (WALSKI et al., 1987), alterada por Kurek e Ostfeld (2014) e utilizada por Coutinho e Soares (2017). A rede é considerada um sistema de referência pela literatura para uso na análise e na comparação de diferentes algoritmos de otimização (JOLLY et al., 2014).

As duas bombas do sistema, 35 e 36, operam com rotação variável e possuem curvas características distintas. Os padrões de rotação da bomba seguem a proposta de Kurek e Ostfeld (2014) e são apresentados na Figura 2. A velocidade relativa de rotação da bomba é representada por $N$, sendo definida como quociente entre determinada velocidade de rotação $N_{2}$ e a velocidade nominal de rotação $N_{1}$.

\section{RESULTADOS}

\section{Busca da minimização do custo energético e da maximização da confiabilidade hidráulica com penalidade para pressão negativa nos nós da rede}

A busca da operação ótima do sistema de distribuição de água, considerando-se a minimização do custo energético e a maximização da confiabilidade hidráulica, primeiramente foi analisada por meio da limitação da pressão, penalizando soluções que apresentem pressões negativas, a fim de proporcionar vazão nos nós de demanda com pressões adequadas para atender ao abastecimento de água nos pontos de consumo. O não cumprimento da penalidade de pressão negativa nos nós da rede implicaria soluções inviáveis de serem aplicadas em um sistema real ou intermitência no abastecimento de água; portanto a aplicação da penalidade 1 tem o propósito de garantir continuidade do abastecimento ao longo do alcance operacional, além de proporcionar que os níveis operacionais dos reservatórios estejam nos limites exequíveis.

Foram realizadas oito simulações considerando-se a penalidade 1. Aplicando os dados de entrada relativos ao simulador hidráulico e

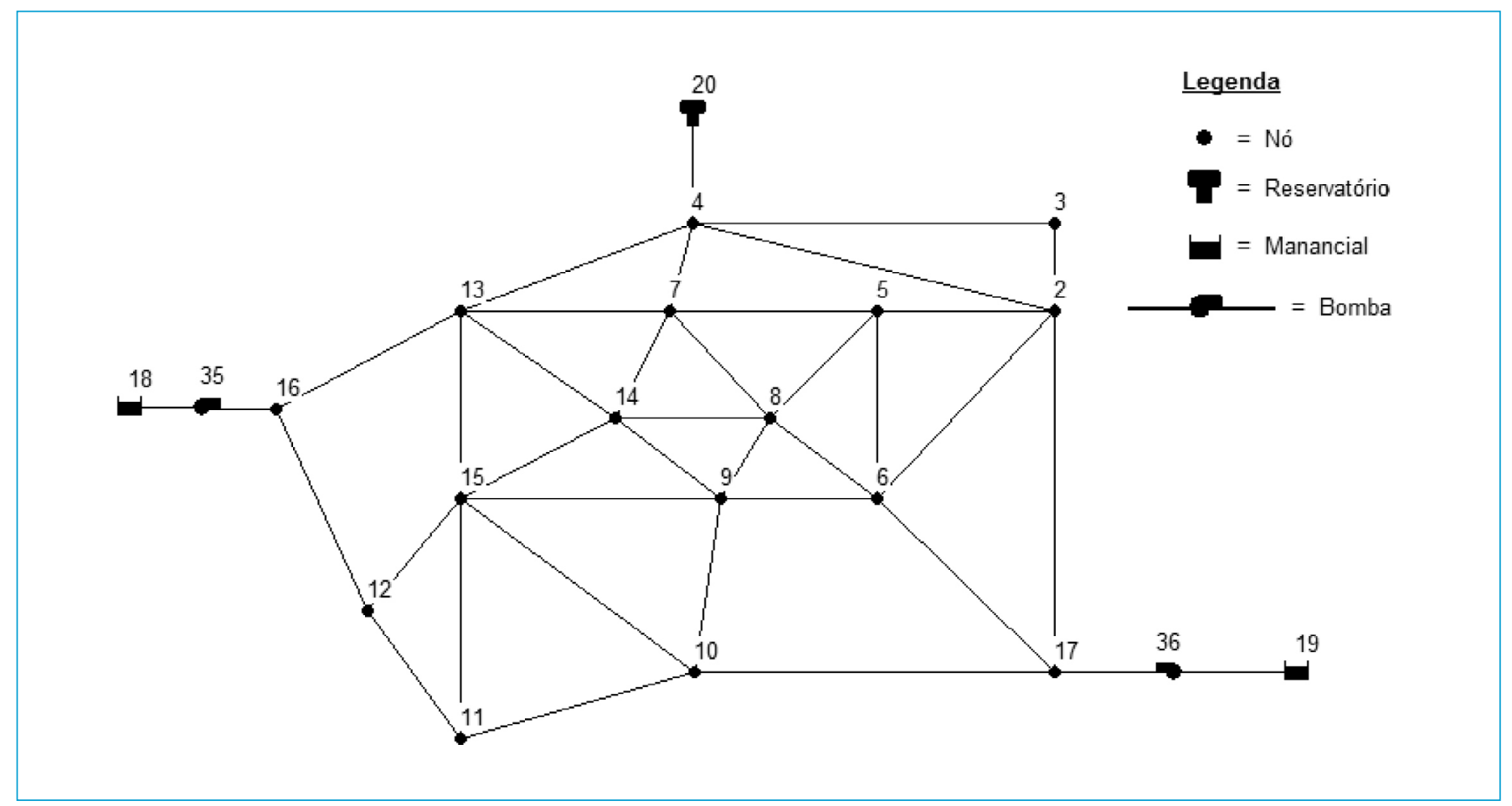

Figura 1 - Rede de distribuição Anytown. 
(a)

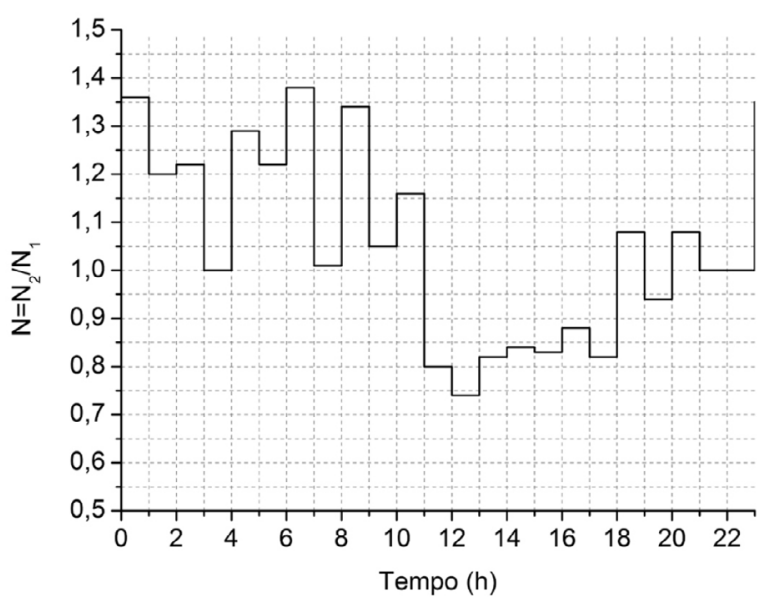

(b)

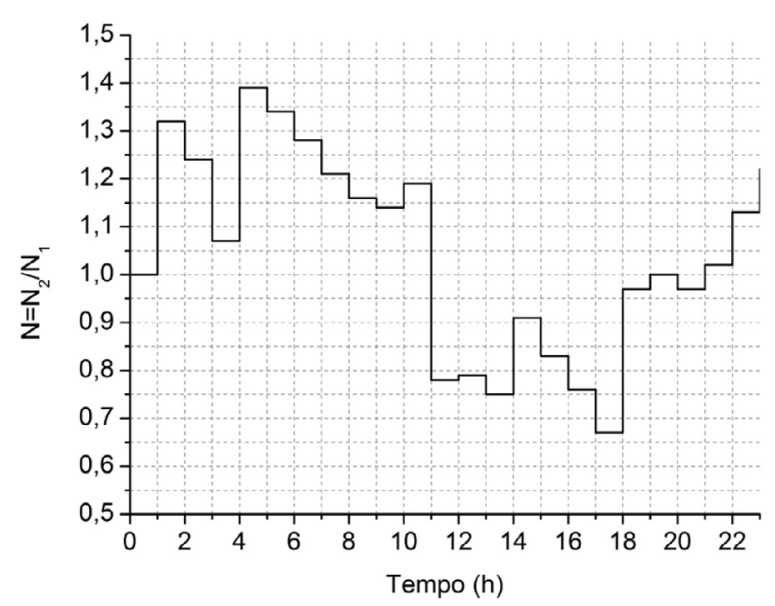

Figura 2 - Padrão de variação da velocidade de rotação: (a) bomba 35 e (b) bomba 36.

ao otimizador operacional e utilizando os parâmetros descritos, geraram-se as frentes Pareto mostradas na Figura 3. Cabe ressaltar que a escolha da melhor solução fica a critério do responsável pela operação do sistema (decisor), tendo em vista que soluções mais viáveis economicamente têm menor confiabilidade hidráulica. Cada ponto representa uma solução operacional para o sistema considerando-se o período das últimas 24 horas para o cálculo das funções objetivo, tendo em vista que a simulação durou 72 horas. A análise dos gráficos mostra que há mudanças em termos de soluções não dominadas, portanto a escolha da melhor solução depende do tipo de estratégia adotada, a fim de reduzir os custos com energia elétrica e/ou maximizar a confiabilidade hidráulica, seguro de que, independentemente da preferência, a estratégia global atende aos objetivos preestabelecidos. A Tabela 1 apresenta o resumo dos resultados obtidos das oito frentes Pareto demonstrados por meio da apresentação da solução de custo mínimo/confiabilidade mínima e custo máximo/confiabilidade máxima, bem como o número de soluções viáveis. Para a frente Pareto 1, por exemplo, o algoritmo encontrou 225 soluções não dominadas num total de 1.000 gerações. Nesse caso, o modelo encontrou uma solução de custo mínimo de R \$ 8.693,02 e uma solução de custo máximo de $\mathrm{R} \$ 10.173,70$ com as respectivas confiabilidades variando entre 5,42994 e 15,52980.

Escolheu-se a frente Pareto 4 com a finalidade de identificar o comportamento das bombas e do reservatório de nível variável. Dessa forma, realizou-se uma simulação hidráulica para cada padrão de rotação das bombas (mínimo e máximo) gerado pelo modelo, apresentadas nas Figuras 4 e 5.
Os resultados obtidos para custo mínimo/confiabilidade mínima foram comparados com os resultados de custo máximo/confiabilidade máxima. Dessa forma, é possível analisar o comportamento do sistema considerando-se os dois extremos. As Figuras 6 e 7 apresentam a vazão das bombas, a carga hidráulica e o nível do reservatório de nível variável (RNV) do sistema de distribuição de água. A linha contínua representa a simulação obtida para o custo mínimo/confiabilidade mínima e a linha pontilhada representa a simulação para a situação de custo máximo/confiabilidade máxima. Pela análise das vazões das bombas 35 e 36, constata-se que tanto a solução de custo mínimo quanto a de custo máximo ocasionam fechamento da bomba 35 em determinadas horas do dia, esvaziando o RNV. Ante isso, percebe-se que não há garantia de suprimento aos consumidores. Nesse caso, de fato o sistema economiza custos de energia elétrica, pelo desligamento da bomba 35 , porém isso acarreta incapacidade de abastecimento do RNV.

Com relação ao nível de água no RNV (Figura 7), evidencia-se que a solução custo mínimo/confiabilidade mínima apresenta valores próximos dos mínimos em grande intervalo de tempo no período de análise; já a solução de custo máximo/confiabilidade máxima proporcionou maior variação dos níveis d'água com melhor aproveitamento do volume disponível, adequando-se à proposta de maior confiabilidade. No entanto, como a ocorrência de desligamento de bomba inviabiliza o atendimento adequado dos consumidores durante as 24 horas do dia, essa solução não é considerada ideal, nesse caso, gerou-se um código de alerta pelo simulador EPANET. Posteriormente, considerou-se a penalidade 2 para assegurar a não ocorrência do fechamento/desligamento de tubos ou bombas durante as últimas 24 horas de análise. 
(1)

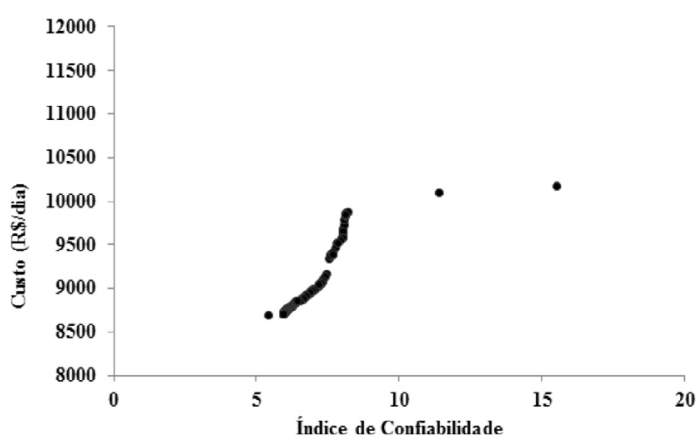

(3)

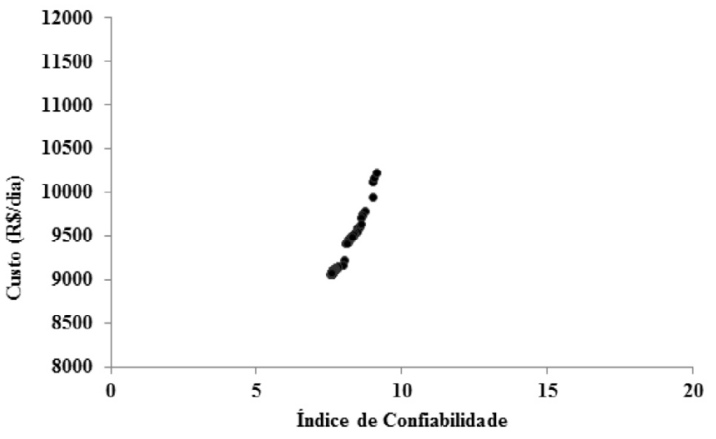

(5)

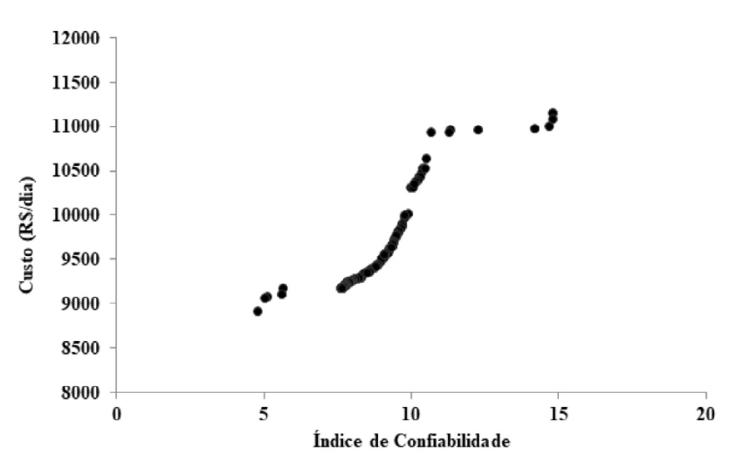

(7)

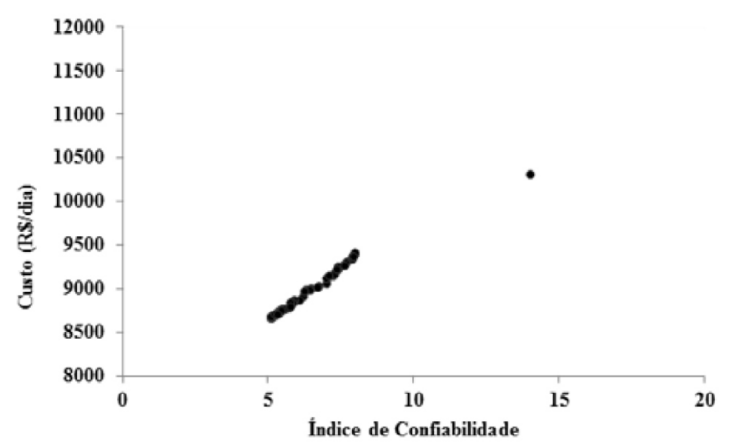

(2)

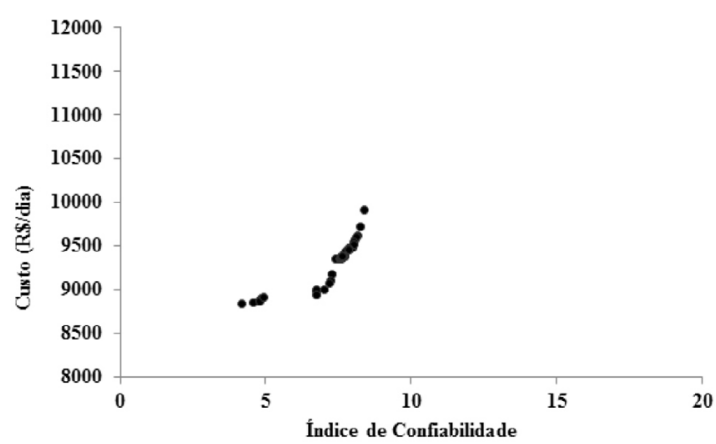

(4)

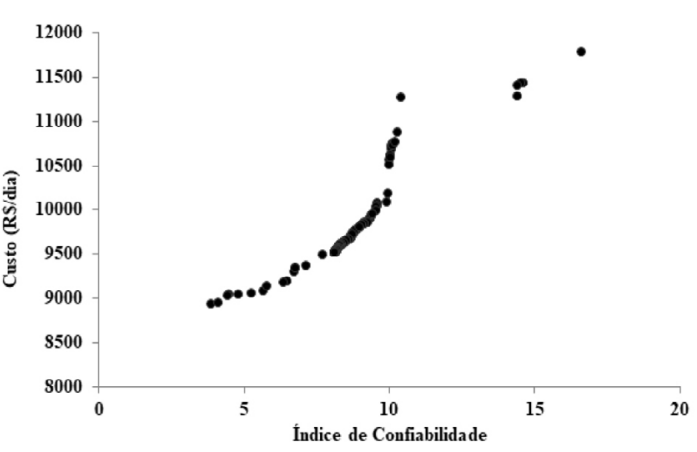

(6)

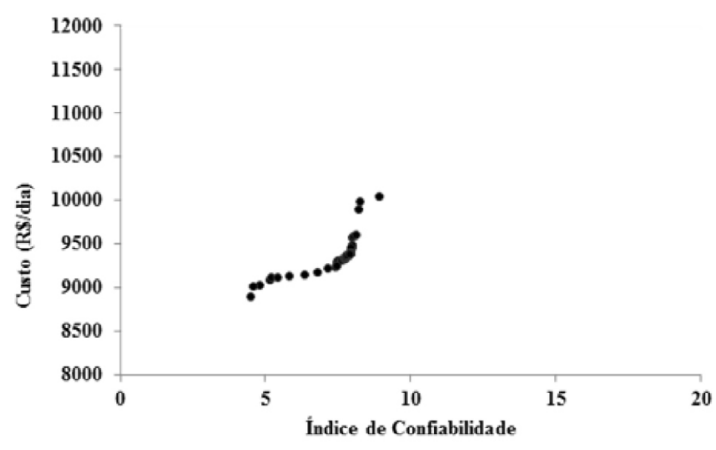

(8)

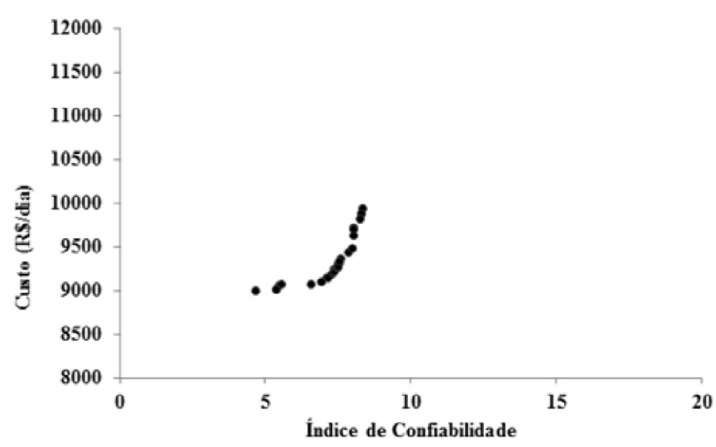

Figura 3 - Soluções não dominadas (frentes Pareto) para a penalidade 1. 
Tabela 1 - Custos mínimo e máximo referentes à penalidade 1.

\begin{tabular}{l|c|c|c|c|c} 
& Custo Mínimo (R\$) & Confiabilidade Mínima & Custo Máximo & Confiabilidade Máxima & Soluções Viáveis \\
\hline Frente de Pareto 1 & $8.693,02$ & 5,42994 & $10.173,70$ & 15,52980 & 225 \\
\hline Frente de Pareto 2 & $8.840,75$ & 4,19840 & $9.911,82$ & 8,36891 & 72 \\
\hline Frente de Pareto 3 & $9.053,41$ & 7,56736 & $10.219,90$ & 13029 & 205 \\
\hline Frente de Pareto 4 & $8.949,64$ & 3,84620 & $11.794,90$ & 14,57750 & 285 \\
\hline Frente de Pareto 5 & $8.916,46$ & 4,76605 & $11.162,90$ & 8,92897 & 235 \\
\hline Frente de Pareto 6 & $8.900,96$ & 4,50098 & $10.041,90$ & 14,01430 & 6 \\
\hline Frente de Pareto 7 & $8.667,36$ & 5,10895 & $10.308,50$ & 8,34193 & 100 \\
\hline Frente de Pareto 8 & $8.995,99$ & 4,65668 & $9.939,47$ & 28 \\
\hline
\end{tabular}

(a)

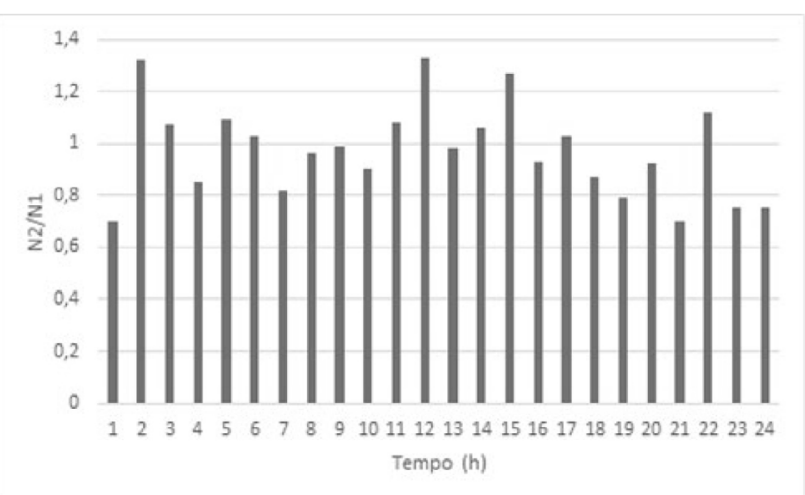

(b)

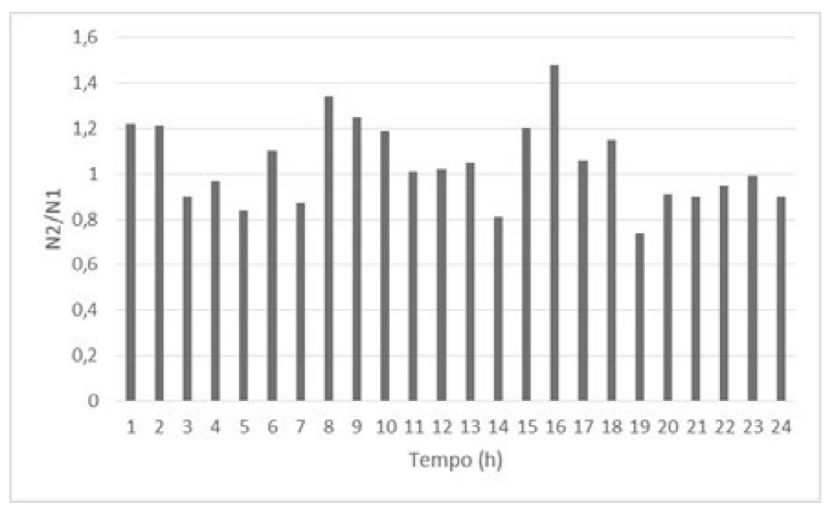

Figura 4 - Padrão de rotação para mínimo custo/confiabilidade da bomba (a) 35 e (b) 36 -frente Pareto 4.

(a)

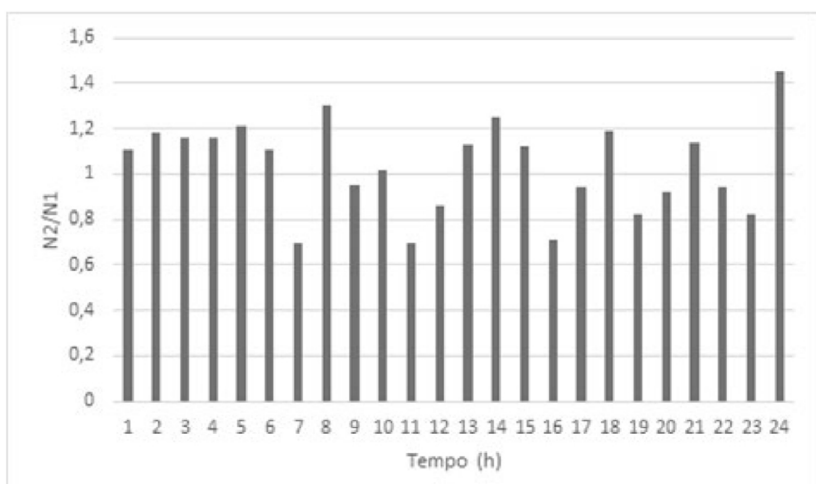

(b)

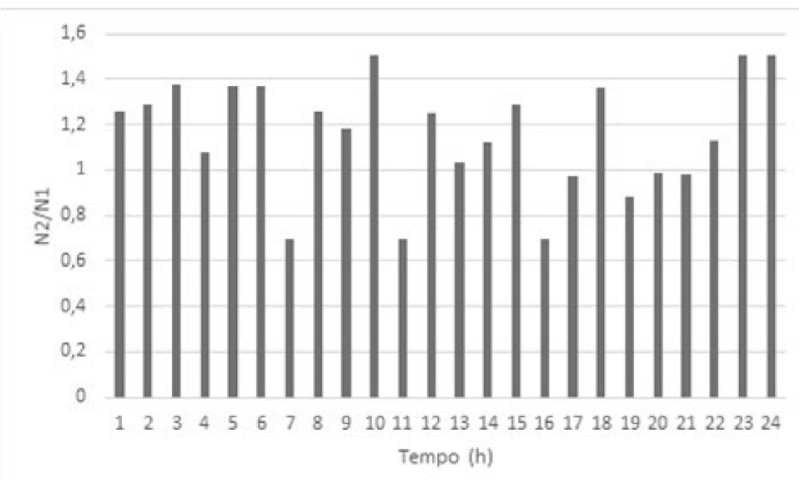

Figura 5 - Padrão de rotação para máximo custo/confiabilidade da bomba (a) 35 e (b) 36 -frente Pareto 4. 
(a)

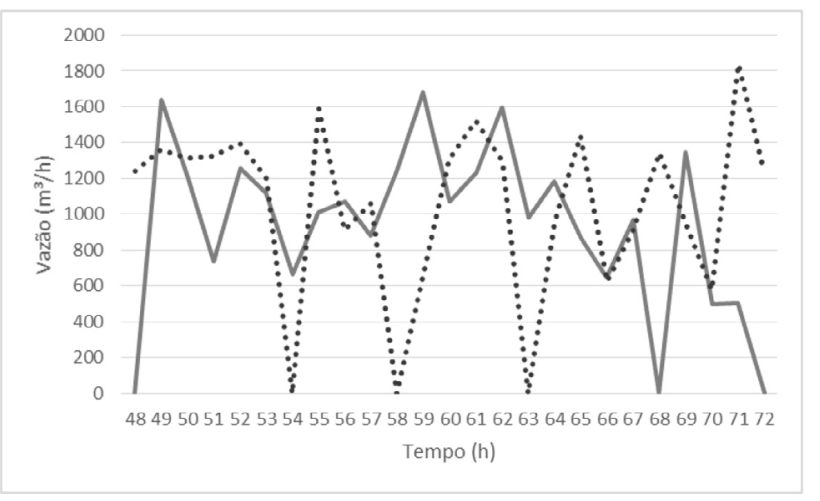

(b)

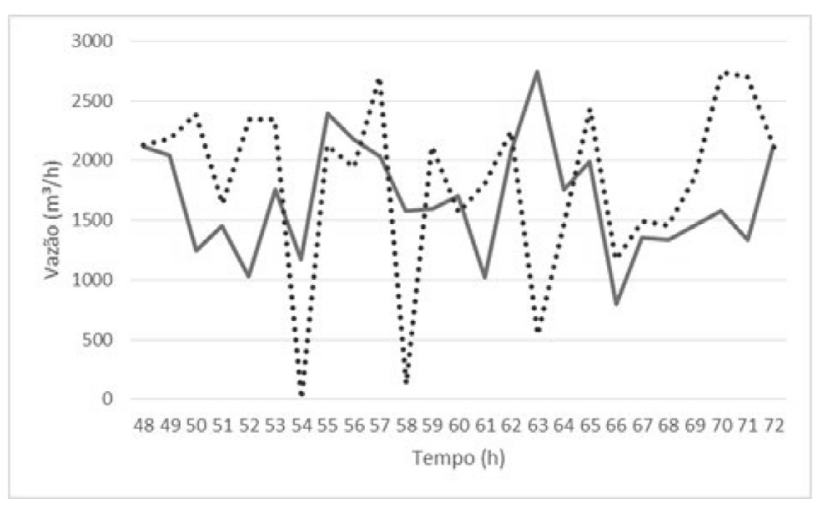

Figura 6 - Vazão da bomba (a) 35 e (b) 36 (frente Pareto 4). A linha contínua representa a simulação obtida para o custo mínimo e confiabilidade mínima, e a linha pontilhada representa a simulação para a situação de custo máximo e confiabilidade máxima.

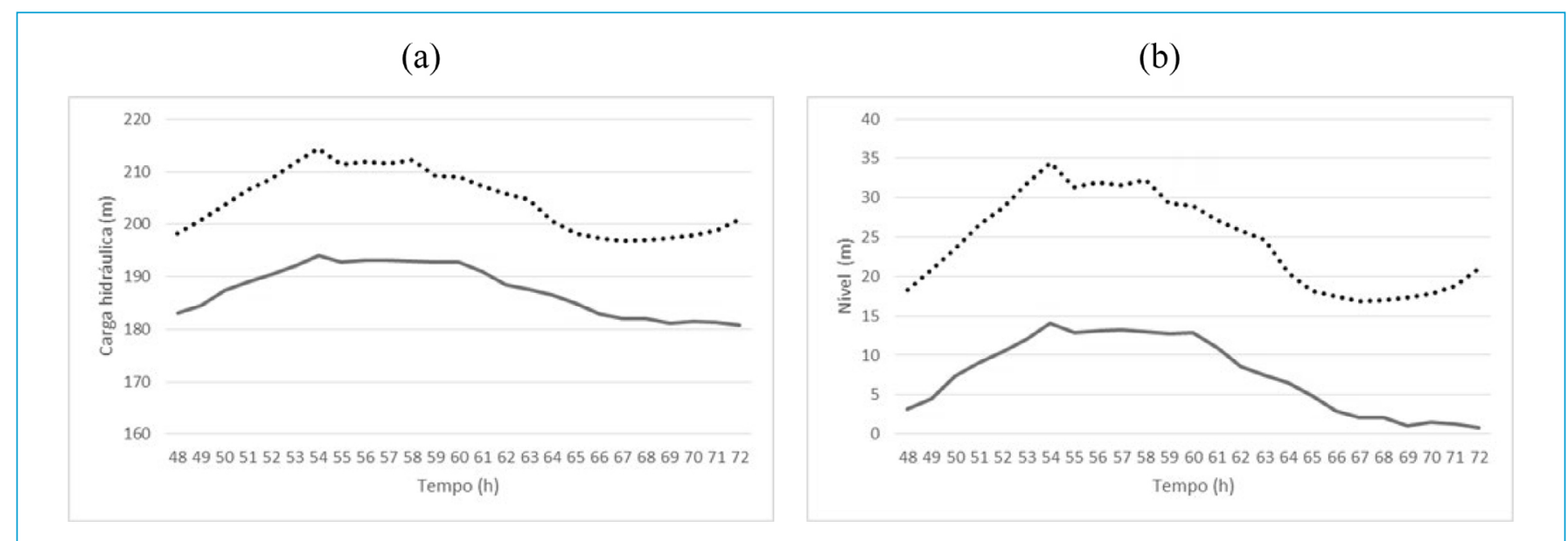

Figura 7 - (a) Carga hidráulica e (b) nível da água do reservatório de nível variável (frente Pareto 4). A linha contínua representa a simulação obtida para o custo mínimo e a confiabilidade mínima, e a linha pontilhada representa a simulação para a situação de custo máximo e confiabilidade máxima.

\section{Busca da minimização do custo energético e da maximização da confiabilidade hidráulica com penalidade para pressão negativa nos nós da rede e fechamento/desligamento de tubos e/ou bombas}

Com a penalidade 1 aplicada, não foi garantida continuidade no abastecimento pelo desligamento da bomba 35, e, assim, aplicou-se a penalidade 2, que prevê, além da análise da pressão negativa nos nós, a penalização pelo fechamento ou desligamento de tubos e bombas no sistema de distribuição de água. Obtiveram-se 10 frentes Pareto, representadas na Figura 8. A Tabela 2 apresenta o resumo dos resultados das 10 frentes Pareto. As Figuras 9 e 10 indicam os resultados dos padrões de rotação das bombas referentes à frente Pareto 11. As vazões bombeadas são mostradas na Figura 11, e a carga hidráulica no RNV é mostrada na Figura 12.
O nível de água no RNV para as soluções de máxima confiabilidade hidráulica permanece acima das soluções de mínima confiabilidade, e esse fato demonstra que a manutenção do nível mínimo de água no reservatório não aumenta a confiabilidade do sistema. Todas as frentes Pareto apresentadas para atenderem à penalidade 2 estão adequadas com as propostas referentes às últimas 24 horas de análise.

Com relação às rotações obtidas para as bombas pelo modelo de otimização, verifica-se que a variação de rotação é mantida em um intervalo, atingindo no máximo 1,5. Pela aplicação da penalidade 2, qualquer solução encontrada pelo modelo garante economia para a operação do sistema, ainda que a confiabilidade varie de acordo com os custos, sendo observada variação de até $77 \%$ entre confiabilidades mínima e máxima. 

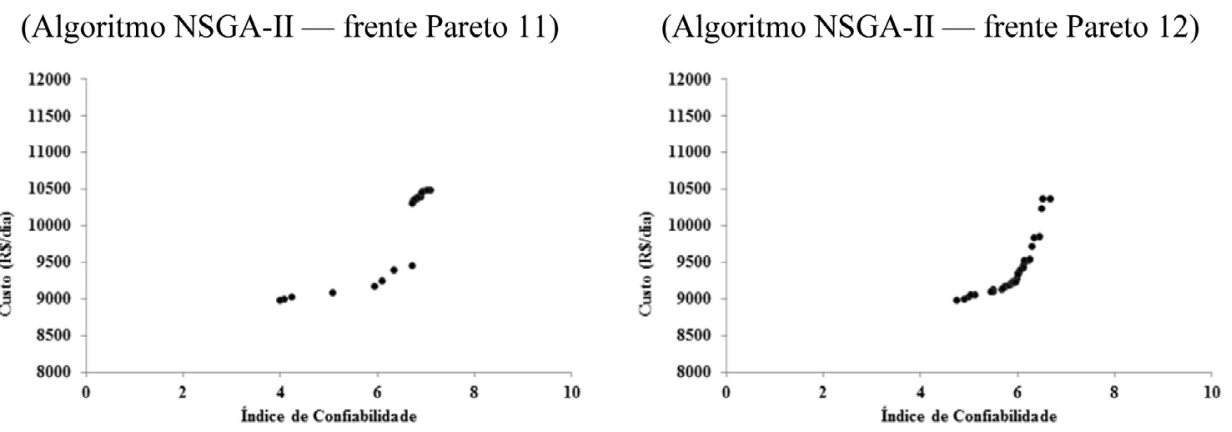

(Algoritmo NSGA-II — frente Pareto 13)

(Algoritmo NSGA-II — frente Pareto 14)
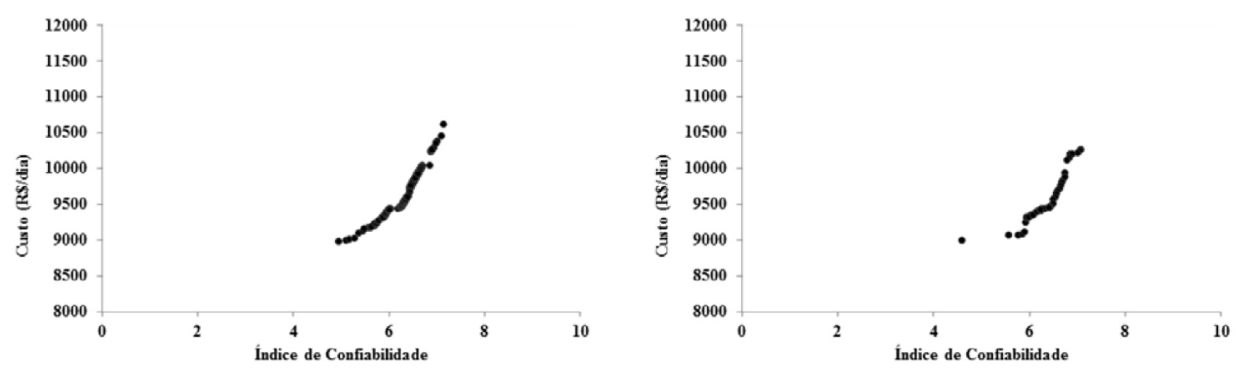

(Algoritmo NSGA-II - frente Pareto 15)

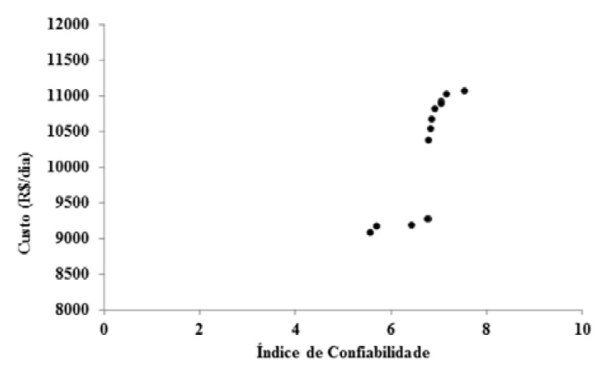

(Algoritmo NSGA-II - frente Pareto 16)

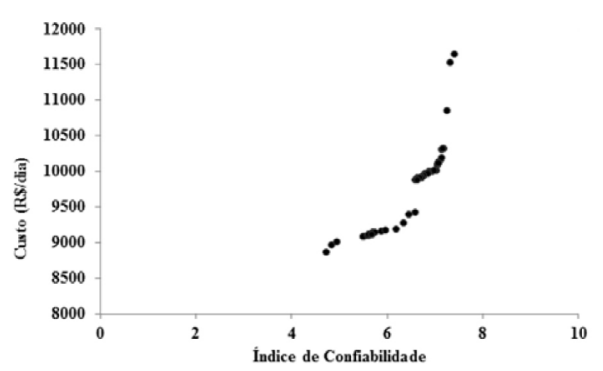

(Algoritmo NSGA-II - frente Pareto 17)

(Algoritmo NSGA-II — frente Pareto 18)
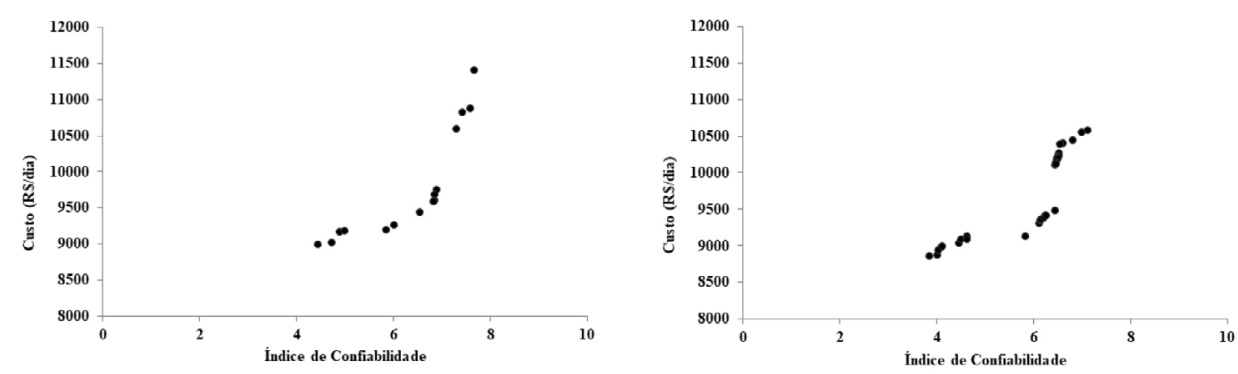

(Algoritmo NSGA-II — frente Pareto 19)

(Algoritmo NSGA-II — frente Pareto 20)
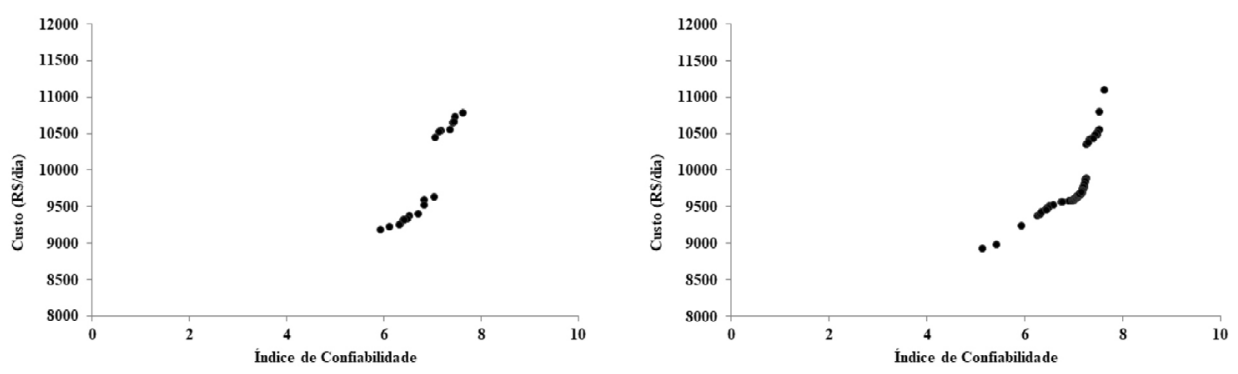

Figura 8 - Soluções não dominadas (frentes Pareto) para a penalidade 2. 
Tabela 2 - Custos mínimo e máximo referentes à penalidade 2.

\begin{tabular}{|c|c|c|c|c|c|}
\hline & Custo Mínimo (R\$) & Confiabilidade Mínima & Custo Máximo (R\$) & Confiabilidade Máxima & Soluções Viáveis \\
\hline Frente de Pareto 11 & $8.990,60$ & 4,00156 & $10.494,00$ & 7,08799 & 30 \\
\hline Frente de Pareto 12 & $8.984,51$ & 4,74961 & $10.375,50$ & 6,66405 & 47 \\
\hline Frente de Pareto 13 & $8.986,94$ & 4,94375 & $10.620,30$ & 7,14478 & 401 \\
\hline Frente de Pareto 14 & $9.003,26$ & 4,59915 & $10.265,30$ & 7,07423 & 53 \\
\hline Frente de Pareto 15 & 8.864,99 & 4,72176 & $10.861,00$ & 7,25652 & 57 \\
\hline Frente de Pareto 16 & $9.081,93$ & 5,56339 & $11.081,10$ & 7,53912 & 13 \\
\hline Frente de Pareto 17 & $9.000,02$ & 4,43312 & $11.416,80$ & 7,65921 & 16 \\
\hline Frente de Pareto 18 & $8.870,20$ & 3,83597 & $10.585,20$ & 7,1113 & 32 \\
\hline Frente de Pareto 19 & $9.186,02$ & 5,92434 & $10.792,60$ & 7,60928 & 20 \\
\hline Frente de Pareto 20 & $8.930,46$ & 5,12633 & $11.109,90$ & 7,61304 & 154 \\
\hline
\end{tabular}

(a)

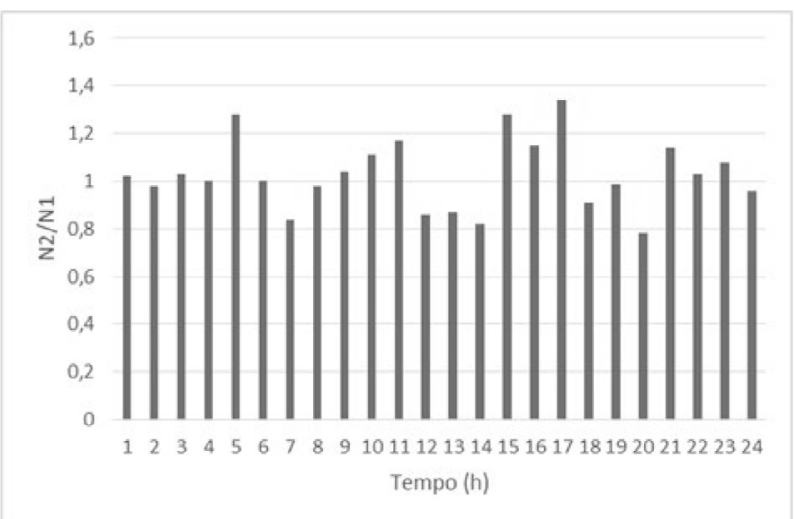

(b)

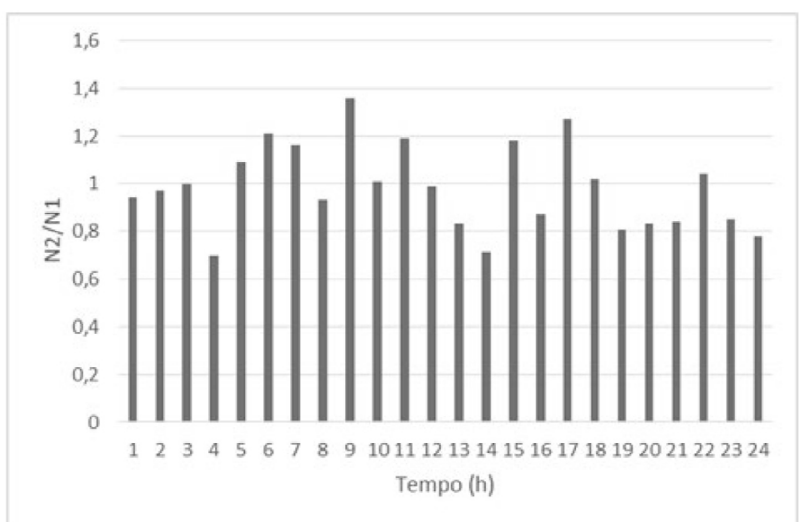

Figura 9 - Padrão de rotação para mínimo custo/confiabilidade da bomba (a) 35 e (b) 36 -frente Pareto 11.

(a)

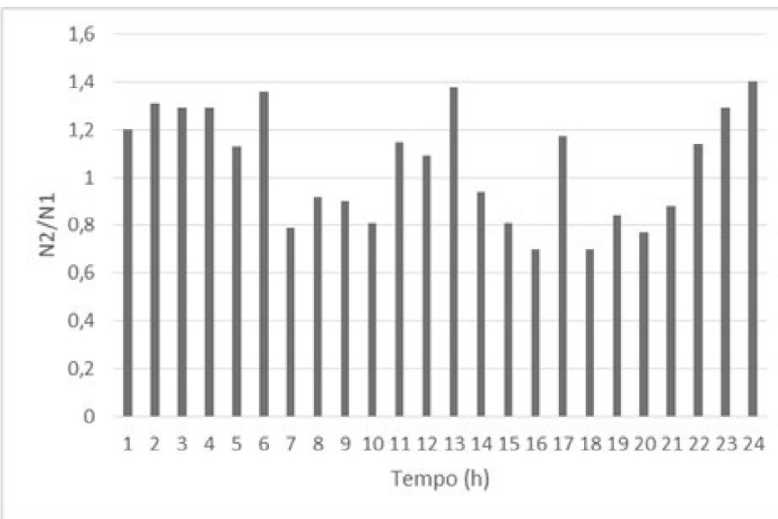

(b)

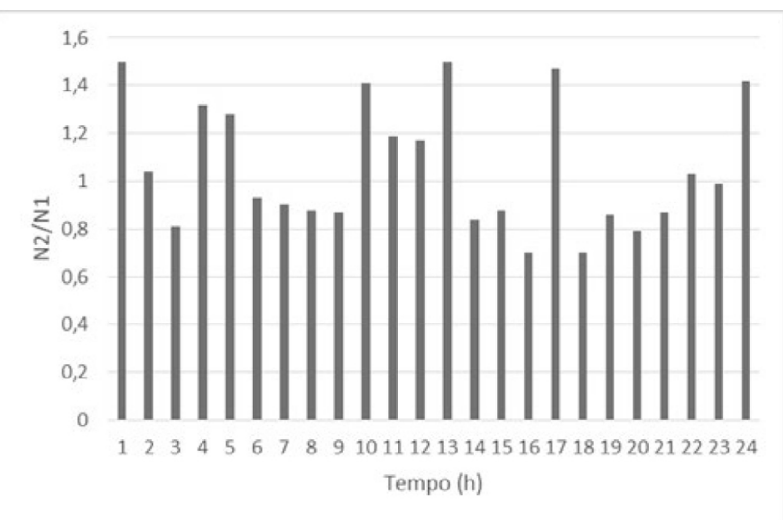

Figura 10 - Padrão de rotação para máximo custo/confiabilidade da bomba (a) 35 e (b) 36 -frente Pareto 11. 
(a)

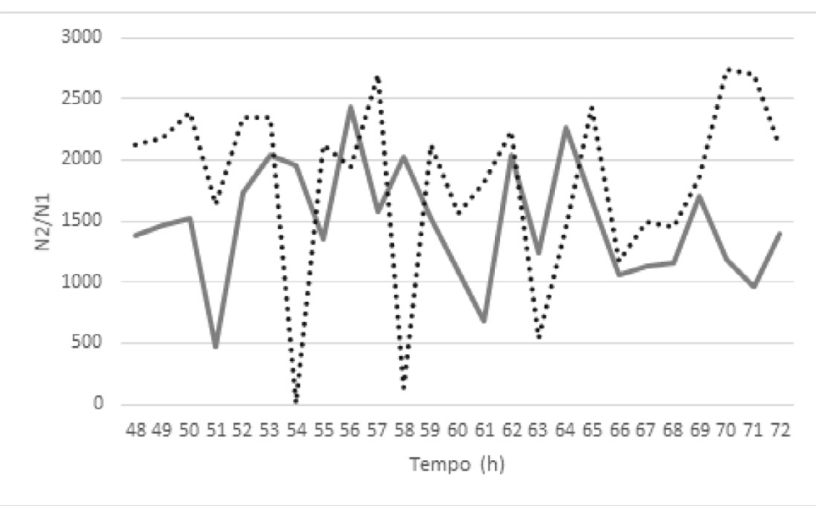

(b)

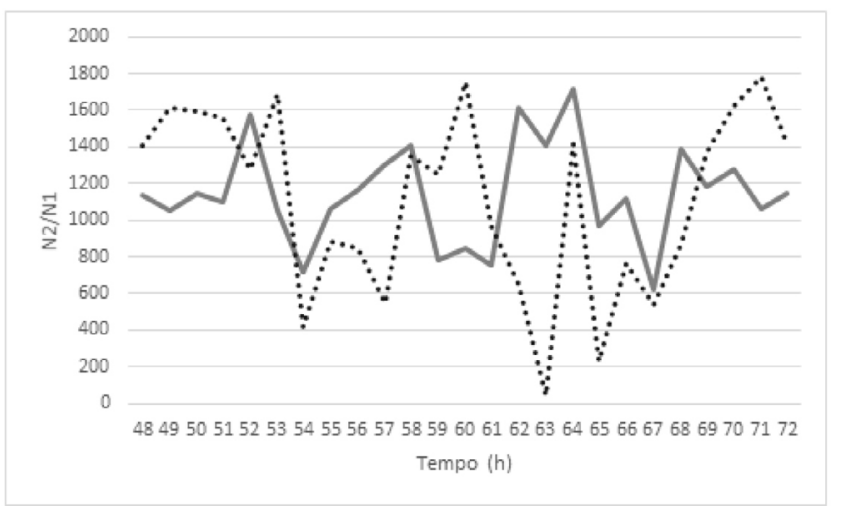

Figura 11 - Vazão da bomba (a) 35 e (b) 36 - frente Pareto 11. A linha contínua representa a simulação obtida para o custo mínimo e a confiabilidade mínima, e a linha pontilhada representa a simulação para a situação de custo máximo e confiabilidade máxima.

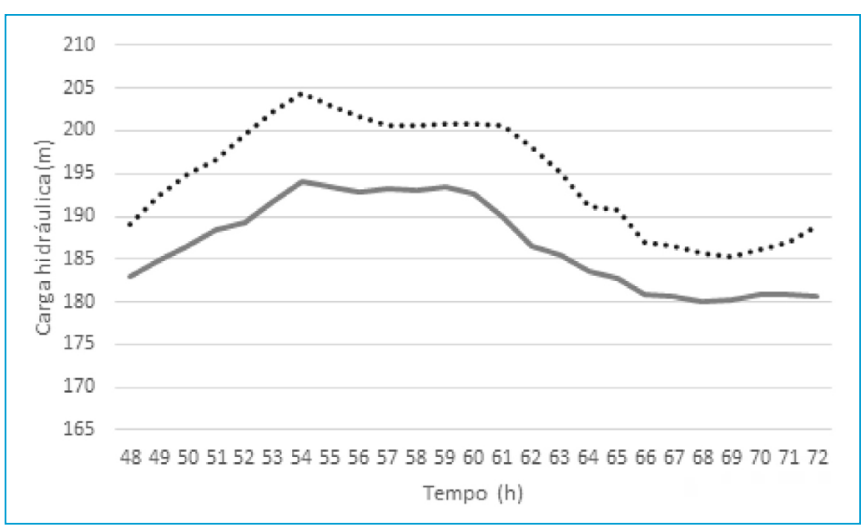

Figura 12 - Carga hidráulica no reservatório de nível variável - frente Pareto 11. A linha contínua representa a simulação obtida para o custo mínimo e a confiabilidade mínima, e a linha pontilhada representa a simulação para a situação de custo máximo e confiabilidade máxima. uma vez que as duas estações elevatórias contam, cada uma, com apenas um conjunto motor-bomba. A necessidade de bombeamento nas 24 horas, por causa da alta demanda do sistema, impediu o desligamento das bombas e restrições foram impostas, reduzindo a flexibilidade da operação do sistema de distribuição de água. Kurek e Ostfeld (2014) empregaram a rede Anytown com bombas de rotação variável operando com eficiências fixas, ou seja, sem correção do EPANET para o cálculo da eficiência para diferentes rotações. Além do custo, com tarifa diferente deste trabalho, a segunda função objetivo foi a de maximização da qualidade da água em termos dos parâmetros de desinfecção. Kurek e Ostfeld (2014) obtiveram custo mínimo de US\$ 4.100,00, aproximadamente, e, neste trabalho, o custo mínimo obtido foi de R\$8.864,99.

\section{CONCLUSÕES}

Os resultados apresentados demonstram a validade do modelo desenvolvido para situações que colocam em risco a operação do sistema e a distribuição de água. De acordo com Cheung (2004), para uma determinada situação hipotética, a solução ideal seria aquela que, além de satisfazer as restrições preestabelecidas, apresente um déficit de pressão em torno de $6 \mathrm{~m}$ em determinado período do dia. Os resultados obtidos para os dois objetivos previamente definidos demonstram a eficácia do modelo, visto que, principalmente com a adoção da penalidade 2 , apresenta pressões adequadas nos nós e nível adequado de água no reservatório.

Trabalhos da literatura apresentam resultados para o problema de Anytown, incorporando outras medidas de desempenho hidráulico e custo, além de diferentes restrições e penalidades. Neste trabalho, o número de soluções não dominadas pode ser considerado pequeno,
Neste trabalho, desenvolveu-se um modelo computacional multiobjetivo aplicado à otimização da operação de sistemas de distribuição de água para possibilitar máximas eficiência energética e confiabilidade hidráulica, utilizando-se bombas de rotação variável. Com o objetivo de favorecer soluções não dominadas e, portanto, garantir distribuição de água de maneira adequada, empregaram-se penalidades que restringiram soluções que apresentassem pressões negativas nos nós ou fechamento/desligamento de tubos e/ou bombas.

O modelo proposto consistiu na integração do algoritmo genético evolucionário multiobjetivo NSGA-II ao simulador hidráulico proposto por Coutinho e Soares (2017), que apresenta correção do cálculo da eficiência de bombas de rotação variável no software EPANET 2. A verificação do modelo utilizou a rede hipotética de Anytown, exposta por Walski et al. (1987). A confiabilidade do sistema mostrou-se adequada 
com a aplicação do índice de resiliência modificado de Todini (2000), visto que as regras operacionais definidas pelo modelo obedeceram às restrições impostas nas penalidades, a fim de garantir distribuição de água de forma adequada. As funções objetivo para minimização dos custos de energia elétrica e maximização da confiabilidade, em conjunto com as restrições impostas, foram utilizadas de forma que validassem o modelo desenvolvido.

Aplicando-se penalidade para pressões negativas nos nós, obtiveram-se os planos esperados para o funcionamento das bombas, considerando-se que tais soluções não são consideradas ideais por não garantirem abastecimento adequado em virtude do desligamento de bombas. A minimização dos custos com energia elétrica foi alcançada; no entanto, o simulador gerou avisos de alerta em decorrência do desequilíbrio do sistema ocasionado pelo desligamento de bombas.

Com a aplicação da penalidade que restringia tanto a pressão negativa nos nós quanto o fechamento e o desligamento dos tubos e bombas, verificou-se a obtenção de resultados fidedignos para as duas otimizações propostas. Assim, os resultados demonstraram a validade do modelo proposto para a otimização operacional de sistemas de distribuição de água, ficando a cargo do operador (decisor) a escolha da solução que lhe for conveniente.

Com relação a possíveis melhorias, destaca-se a necessidade de aplicação do modelo em um sistema real de distribuição de água, com a incorporação de outros critérios, por exemplo, qualidade da água e perdas por vazamentos.

\section{REFERÊNCIAS}

ADDAMS, L.; BOCCALETTI, G.; KERLIN, M.; STUCHTEY, M. (2OO9) Charting our water future: Economic frameworks to informe decision-making. Nova York: McKinsey \& Company.

AGÊNCIA NACIONAL DE ENERGIA ELÉTRICA (ANEEL). (2014) Banco de Informações de Geração. ANEEL. Disponível em: <http:// relatorios.aneel.gov.br/_layouts/xIviewer.aspx?id=/RelatoriosSAS/ RelSampClasseCons.xIsx\&Source=http://relatorios.aneel.gov.br/ RelatoriosSAS/Forms/Allltems.aspx\&Default|temOpen=1>. Acesso em: 8 ago. 2017.

ATKINSON, S.; FARMANI, R.; MEMON, F.A.; BUTLER, D. (2014) Reliability indicators for water distribution system design: Comparison. Journal of Water Resources Planning and Management, v. 140, n. 2, p. 160168. https://doi.org/10.1061/(ASCE)WR.1943-5452.0000304

CANDELIERI, A.; PEREGO, R.; ARCHETTI, F. (2018) Bayesian optimization of pump operations in water distribution systems. Journal of Global Optimization, v. 71, p. 213-235.

CHANG, Y.; CHOI, G.; KIM, J.; BYEON, S. (2018) Energy Cost Optimization for Water Distribution Networks Using Demand Pattern and Storage Facilities. Sustainability, v. 10, n. 4, p. 118. https:// doi.org/10.3390/su10041118

CHEUNG, P. B. (2004) Análise de reabilitação de redes de distribuição de água para abastecimento via algoritmos genéticos multiobjetivo. Tese (Doutorado) - Escola de Engenharia de São Carlos, Universidade de São Paulo, São Carlos, 2004.

CONNOR, R. (2015) The United Nations world water development report 2015: Water for a sustainable world. Technical Report. UNESCO.

COUTINHO, R.S.; SOARES, A.K. (2017) Simulação de bombas com velocidade de rotação variável no EPANET. Engenharia Sanitária e Ambiental, v. 22, n. 4, p. 797-808. https://doi.org/10.1590/s141341522017163428
DEB, K.; PRATAP, A.; AGARWAL, S.; MEYARIVAN, T. (2002) A fast and elitist multiobjective genetic algorithm: NSGA-II. IEEE Transactions on Evolutionary Computation, v. 6, n. 2, p. 182-197. https://doi. org/10.1109/4235.996017

DE PAOLA, F.; FONTANA, N.; GIUGNI, M.; MARINI, G.; PUGLIESE, F. (2016) An application of the harmony-search multiobjective (HSMO) optimization algorithm for the solution of pump scheduling problem. Procedia Eng., v. 162, p. 494-502. https://doi. org/10.1016/j.proeng.2016.11.093

FORMIGA, K.T.M.; CHAUDHRY, F.H.; VIEIRA, M.E.A. (2006) Otimização multiobjectivo de redes de abastecimento de água. In: SEMINÁRIO IBEROAMERICANO SOBRE SISTEMAS DE ABASTECIMENTO DE ÁGUA, 6., João Pessoa. Anais...

GIUSTOLISI, O:; LAUCELLI, D.; BERARDI, L. (2013) Operational optimization: Water losses versus energy costs. Journal of Hydraulic Engineering, v. 139, n. 4, p. 410-423. https://doi.org/10.1061/ (ASCE)HY.1943-7900.0000681

JAYARAM, N.; SRINIVASAN, K. (2008) Performance-based optimal design and rehabilitation of water distribution networks using life cycle costing. Water Resources Research, v. 44, n. 1, p. 1-15. https:// doi.org/10.1029/2006WR005316

JOLLY, M.D.; LOTHES, A.D.; BYRON, L.S.; ORMSBEE, L. (2014) Research database of water distribution system models. Journal of Water Resources Planning and Management, v. 140, n. 4, p. 410-416. https://doi.org/10.1061/(ASCE)WR.19435452.0000352

KUREK, W.; OSTFELD, A. (2014) Multiobjective Water Distribution Systems Control of Pumping Cost, Water Quality, and StorageReliability Constraints. Journal of Water Resources Planning and Management, v. 140, n. 2, p. 184-193. https://doi.org/10.1061/(ASCE) WR.1943-5452.0000309 
LINGIREDDY, S.; WOOD, D.J. (1998) Improved operation of water distribution systems using variable-speed pumps. Journal of Energy Engineering, v. 124, n. 3, p. 90-103. https://doi.org/10.1061/ (ASCE)0733-9402(1998)124:3(90)

LIU, F.; OUEDRAOGO, S.; MANGHEE, S.; DANILENKO, A. (2012) A primer on energy efficiency for municipal water and wastewater utilities. Technical report. World Bank.

OSTFELD, A. (2004) Reliability analysis of water distribution systems. Journal of Hydroinformatics, v. 6, n. 4, p. 281-294. https:// doi.org/10.2166/hydro.2004.0021

ROSSMAN, L.A. (2000) EPANET 2 users manual. Cincinnati: U.S. Environmental Protection Agency.

SIMPSON, A.R.; MARCHI, A. (2013) Evaluating the approximation of the affinity laws and improving the efficiency estimate for variable speed pumps. Journal of Hydraulic Engineering, v. 139, n. 12, p. 13141317. https://doi.org/10.1061/(ASCE)HY.1943-7900.0000776

SOUSA, A.C. (2013) Otimização hidroenergética da operação de sistemas de distribuição de água. Dissertação (Mestrado) - Escola de Engenharia Civil e Ambiental, Universidade Federal de Goiás, Goiânia.

TODINI, E. (2000) Looped water distribution networks design using a resilience index based heuristic approach. Urban Water, v. 2, n. 2, p. 115-122. https://doi.org/10.1016/S14620758(00)00049-2

WALSKI, T.M.; BRILL JR., E.D.; GESSLER, J.; GOULTER, I.C.; JEPPSON, R.M.; LANSEY, K.; LEE, K.L.; LIEBMAN, J.C.; MAYS, L.; MORGAN, D.R.; ORMSBEE, L. (1987) Battle of the network models: Epilogue. Journal of Water Resources Planning and Management, v. 113, n. 2, p. 191-203. https://doi.org/10.1061/ (ASCE)0733-9496(1987)113:2(191)

WALSKI, T.M.; CHASE, D.V.; SAVIC, D.A.; GRAYMAN, W.; BECKWITH, S.; KOELLE, E. (2003) Advanced water distribution modeling and Management. Waterbury: Haestad Press.

ZHANG, H.; XIA, X.; ZHANG, J. (2012) Optimal sizing and operation of pumping systems to achieve energy efficiency and load shifting. Electric Power Systems Research, v. 86, p. 41-50. https://doi. org/10.1016/j.epsr.2011.12.002 